\title{
Stability Enhancement in Two Bus and Multi Bus Power System Using SSSC
}

\author{
Snehal S. Patel ${ }^{1}$, Mohammed Irfan Siddiqui ${ }^{2}$ \\ ${ }^{1}$ PG Student at dept. of Electrical Engineering, Parul Institute of Engineering and Technology \\ ${ }^{2}$ Assistant Professor, Electrical Department, Parul Institute of Engineering \& Technology
}

\begin{abstract}
In this study, a very efficient approach to control the power flow though the transmission line is given. A static synchronous series compensator (SSSC) is used as controller. It controls the active and reactive power as well as damping power system oscillation in transient mode. The SSSC is equipped with a source of energy in DC link can supply or absorb the reactive power to or from the transmission line. Simulation results are obtained for the selected bus-2 in two machine power system and multi bus system which shows the efficiency of this compensator as one of the FACTS devices member in controlling the power flow, achieving the desired value of active and reactive powers, and damping the power oscillation.
\end{abstract}

Keywords: SSSC, VSC, FACTS, reactive power compensation, PI controller.

\section{Introduction}

Flexible AC transmission line consists of static devices used in $\mathrm{AC}$ transmission system to enhance the power transfer capability. FACTS devices can overcome the disadvantages of presently used mechanically controlled transmission system. These devices reduce the requirement to build more transmission lines and power plants. Power electronic devices used in FACTS devices have made it possible for controllable series and shunt compensators to control the power flow through transmission line. The flexibility and fast power flow control of transmission system is more important. The power flow of transmission system depends on line impedance, the magnitude of sending and receiving end voltage and phase angle between these voltages. By compensating reactive power is great approach to increase transmission capability of transmission line. Traditionally, in order to control the power flow of the transmission line, the effective line reactance is controlled by using fixed or thyristor-controlled series capacitors or inductors. Recently, a new power flow controller entitled Transmission Line Dynamic Impedance Compensation System, which uses solid-state switching converters, has been proposed.

With the use of the impedance compensation controller, a Static Synchronous Series Compensator (SSSC), which is a solid-state voltage source inverter, injects an almost sinusoidal voltage, of variable magnitude, in series with a transmission line. This approach use power electronic switches, so it has high speed of control and good transient stability during fault. It improves power system stability. In this module, SSSC (static synchronous series compensator) FACTS controller performs to improve power system stability. SSSC series compensator consist voltage source converter (VSC) which generate controllable voltage. This injected voltage kept in quadrature with the line current; it can operate in inductive or capacitive reactance to influence power flow through line. Thus, it controls power flow and improve transient stability of power system.

\section{Configuration of SSSC}

The basic scheme of the SSSC is shown in figure 1. The compensator is equipped with a source of energy, which helps in supplying or absorbing active power to or from the transmission line along with the control of reactive power flow. SSSC is similar to the variable reactance because the injected voltage and current to the circuit by this device are changing depend upon to the system conditions and the loads entering/getting out.

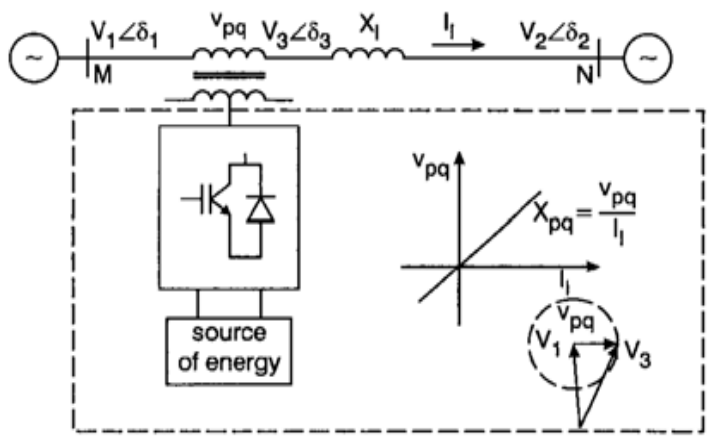

Figure 1: Static synchronous voltage capacitor

\section{Control Scheme}

The Static Synchronous Series Compensator (SSSC) is a series device of the Flexible AC Transmission Systems (FACTS) family using power electronics to control power flow and improve power oscillation damping on power grids. The SSSC is injects a voltage Vs in series with the transmission line where it is connected. As the SSSC does not use any active power source, the injected voltage must stay in quadrature with line current. By varying the magnitude of the injected voltage $\mathrm{Vq}$ in quadrature with current, the SSSC performs the function like a variable reactance compensator either capacitive or inductive. The variation in injected voltage is performed by means of a Voltage-Sourced Converter (VSC) that is connected on the secondary side of a coupling transformer. The VoltageSourced Converter (VSC) uses forced commutated power electronic devices (GTOs or IGBTs) to synthesize a voltage Vconv from a DC voltage.

\section{Volume 5 Issue 6, June 2016} www.ijsr.net 


\section{International Journal of Science and Research (IJSR) \\ ISSN (Online): 2319-7064}

Index Copernicus Value (2013): 6.14 | Impact Factor (2015): 6.391

One side of the converter is connected to the AC system and the other side is connected to a capacitor and battery which in the system we assume DC source as battery. If a dynamic change in system will be occurred, SSSC circuit works such that according to the control circuit in figure.2. The energy of battery will be converted to the ac form by converter and then injecting this voltage to the circuit the changes will be damped appropriately.

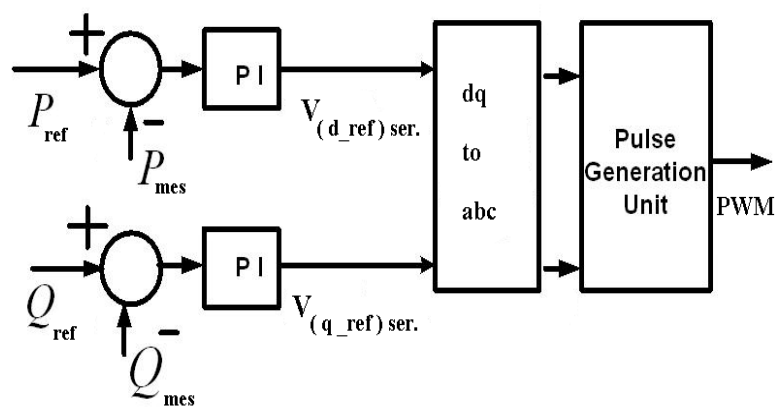

Figure 2: Control circuit

To control the active and reactive powers of bus, the control circuit as shown in figure. 2 is utilized. For controlling the powers, first, sampling from the voltage and current is done and transformed to the $\mathrm{dq} 0$ values. Active and reactive powers of bus-2 are calculated using their voltage and current in dq 0 references and compared with the determined reference and the produced error signal is given to the PI controllers. Adjusting parameters of the PI controllers, we are trying to achieve the zero signal error, such that powers can follow the reference powers precisely. Then, the output of the controllers are transformed to the abc reference and given to the PWM.

\section{Simulation for Two Machine Bus System}

The dynamic performance of SSSC is presented by real time voltage and current waveforms using MATLAB software. In the simulation one SSSC has been utilized to control the power flow in the $500 \mathrm{KV}$ transmission systems.

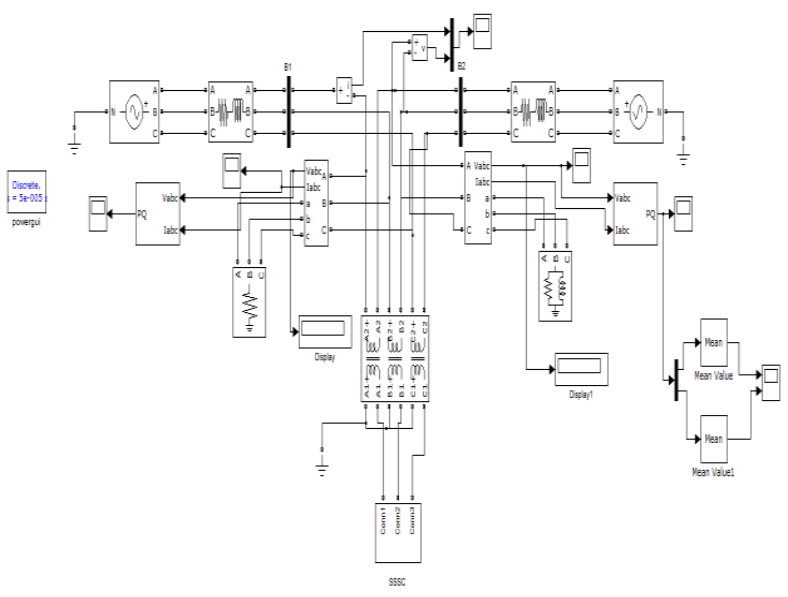

Figure 3: Bus system
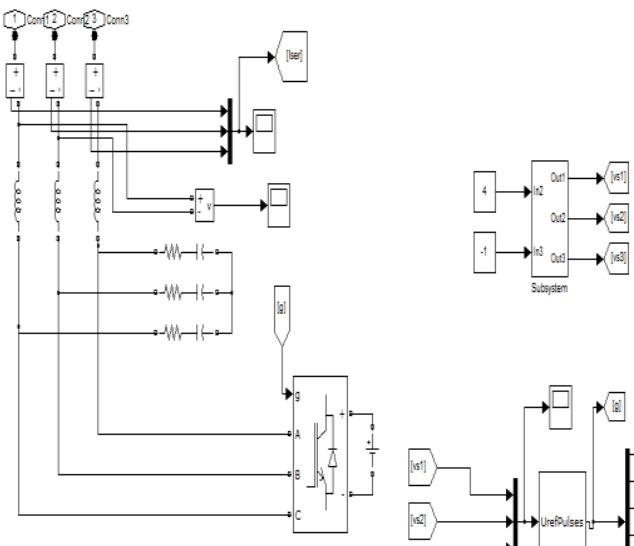

Figure 4: Simulation of SSSC

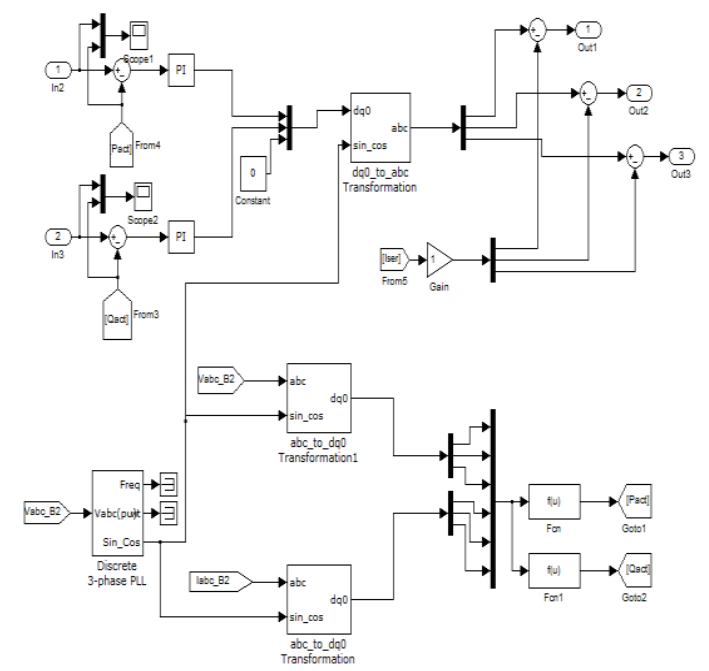

Figure 5: Simulation of control circuit

SSSC has been placed between bus-1 and bus- 2 . The main role of SSSC is controlling the active and reactive powers; beside these SSSC could fairly improve the transient oscillations of system.

After the installation of SSSC, besides controlling the power flow in bus-2 we want to keep constant the voltage value in 1 per unit, hence the power flow is done in the presence of SSSC and the simulation results are as follows. Installing the SSSC, active power damping time will be less than the mode without SSSC and it will be damped faster. Reactive power damping time will be decreased and system will follow the references value with acceptable error.

\section{Simulation Results}

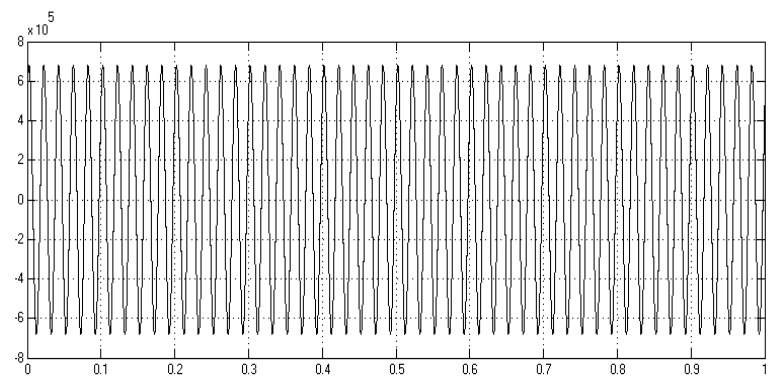

Figure 5: Waveform of bus 2 voltage without sssc

Volume 5 Issue 6, June 2016 www.ijsr.net 
International Journal of Science and Research (IJSR)

ISSN (Online): 2319-7064

Index Copernicus Value (2013): 6.14 | Impact Factor (2015): 6.391

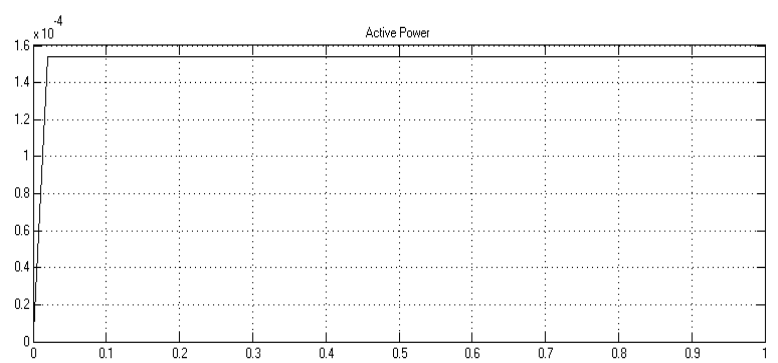

Figure 6: Waveform of active power without sssc

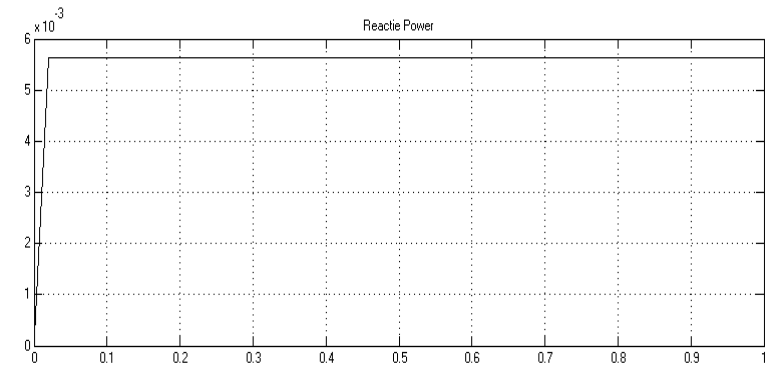

Figure 7: Waveform of reactive power without sssc

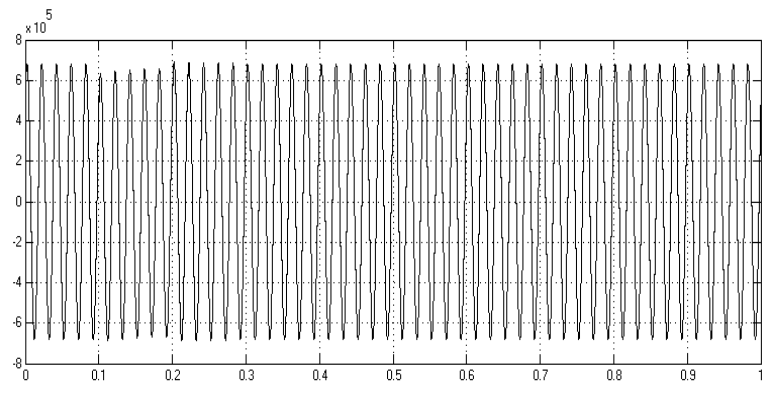

Figure 8: Waveform of bus voltage when inductive load is increased

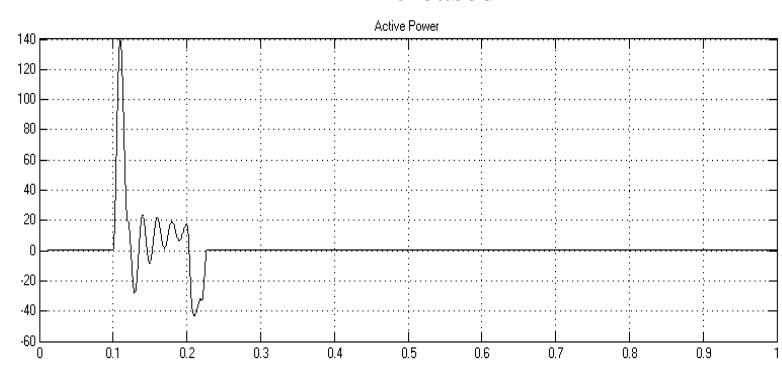

Figure 9: Waveform of active power when inductive load is increased

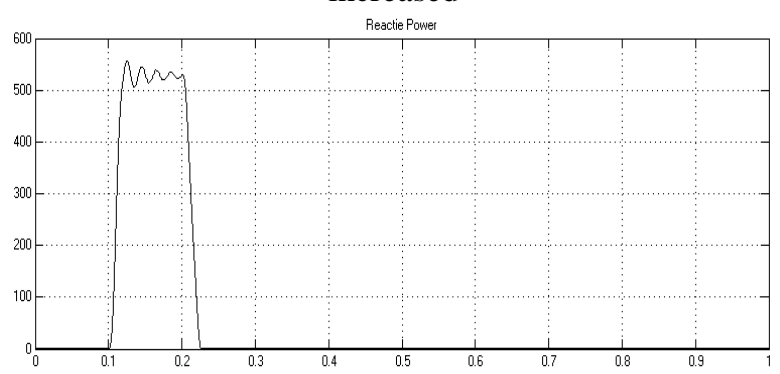

Figure 9: Waveform of reactive power when inductive load is increased

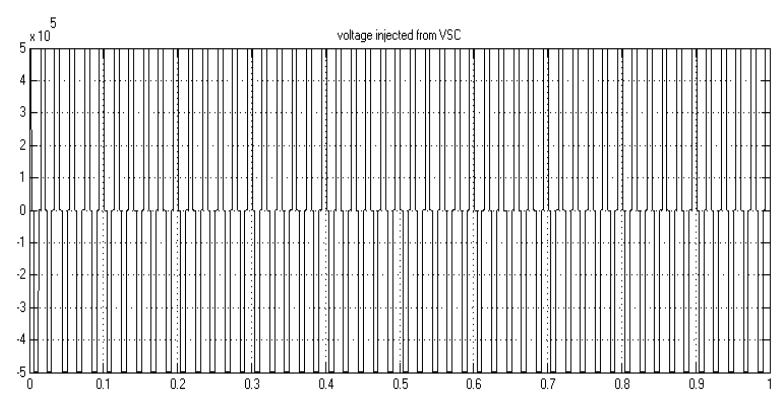

Figure 10: Waveform of voltage injected by VSC

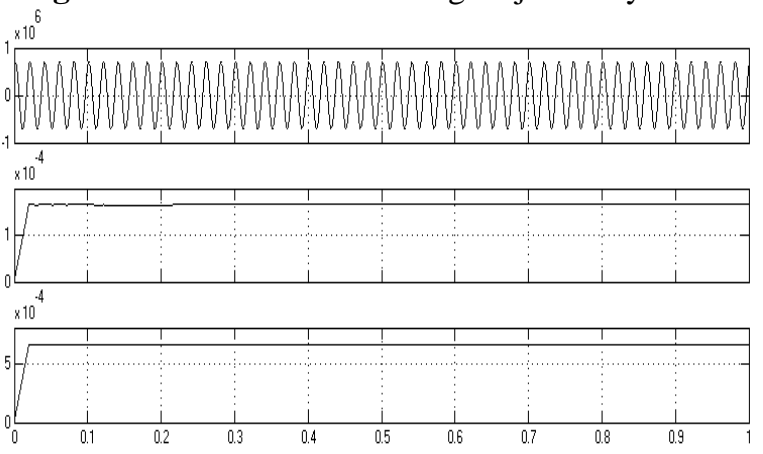

Figure 11: Waveform of voltage, active power and reactive power with sssc

\section{Simulation of multi bus (11 bus) system}

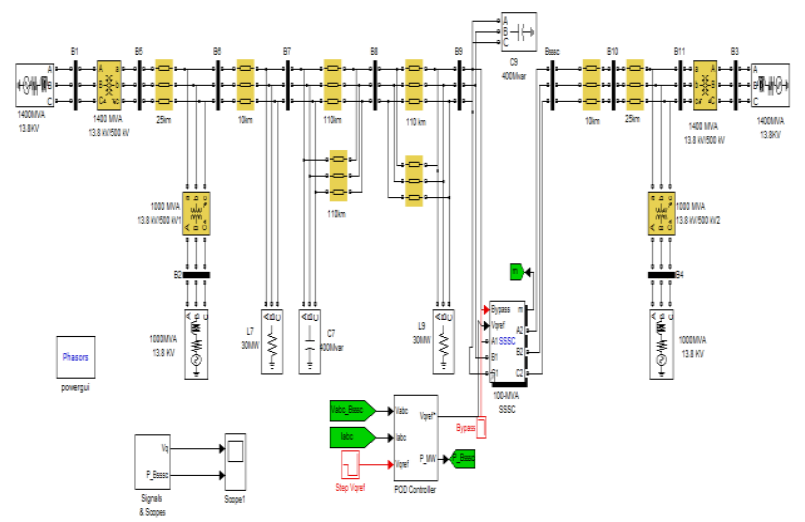

Figure 12: 11- bus system

The three phase voltages of having $13.8 \mathrm{kv}$ are connected by using the $290 \mathrm{~km}$ of transmission line all the way through three phase step up transformers. The system is having the output voltage waveform equivalents to the $500 \mathrm{kv}$ rating of transformers having $1000 \mathrm{MVA}$ and $1400 \mathrm{MVA}$ respectively ratings of transformer of two areas connected by $290 \mathrm{~km}$ transmission line. The loads in both areas having $30 \mathrm{KW}$ resistive loads so preferred that the power is flown from area 1 to 2 . In propose model the SSSC is used in phasor model. The given load of about $60 \mathrm{KW}$ is modelled in which the power absorbed by load is the function of the voltage. Here, POD controller is used to damp power oscillation by injecting Vref and Vinj voltage during ON status of POD controller.

\section{Proposed Control Scheme}

The phase locked loop (PLL) which synchronize the positive sequence component of given line current. To compute the direct axis and quadrature axis components of the AC three phase voltages and current, the output of PLL which is the

\section{Volume 5 Issue 6, June 2016} www.ijsr.net 


\section{International Journal of Science and Research (IJSR) \\ ISSN (Online): 2319-7064}

Index Copernicus Value (2013): 6.14 | Impact Factor (2015): 6.391

phase angle is used. The measurements of voltage will measure the quadrature axis component of positive sequence of voltages $\mathrm{V} 1$ and $\mathrm{V} 2$, and also the dc voltage $\mathrm{Vdc}$.

The voltage regulators of AC and DC system will compute the converter voltage which also having q-axis axis and daxis components and which are also required to obtain the dc voltage and injected voltage. The voltage regulator which gives $\mathrm{Vq}$ value is aided having feed forward regulator which estimate convertor voltage from line current measurement.
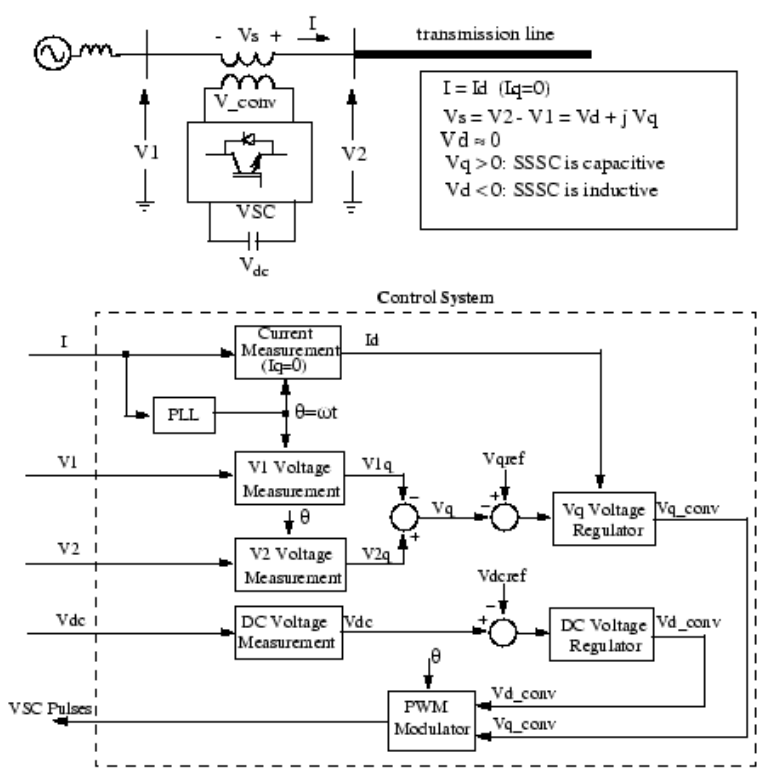

\section{Simulation Results}

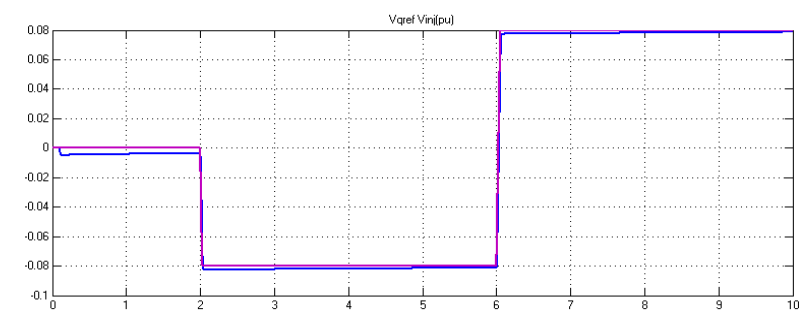

Figure 12: Waveform of voltage without POD

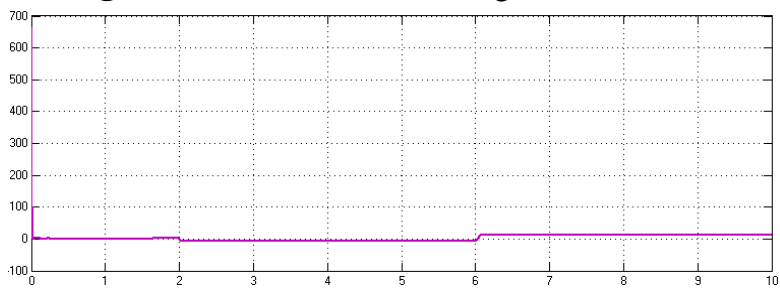

Figure 13: Waveform of active power without POD

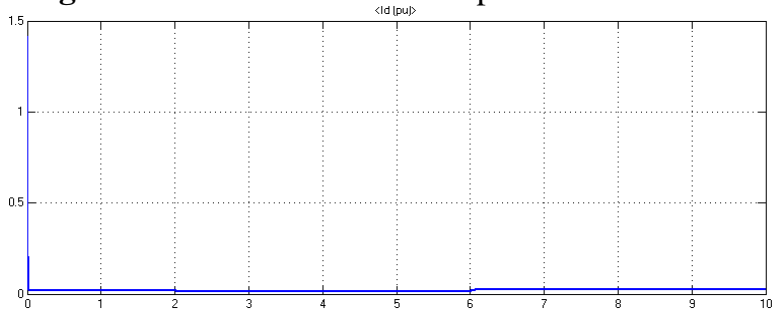

Figure 14: Waveform of Id current without POD

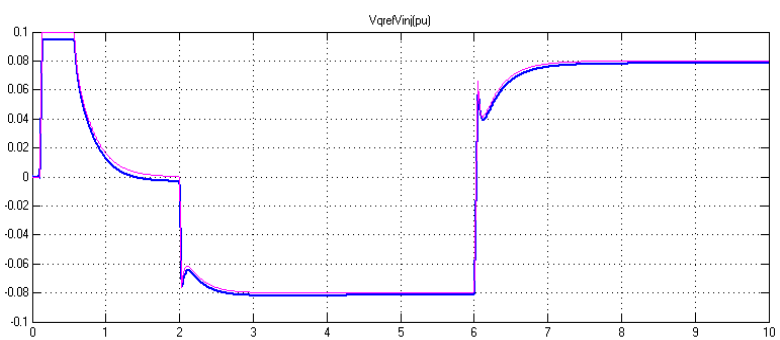

Figure 15: Waveform of voltage with POD

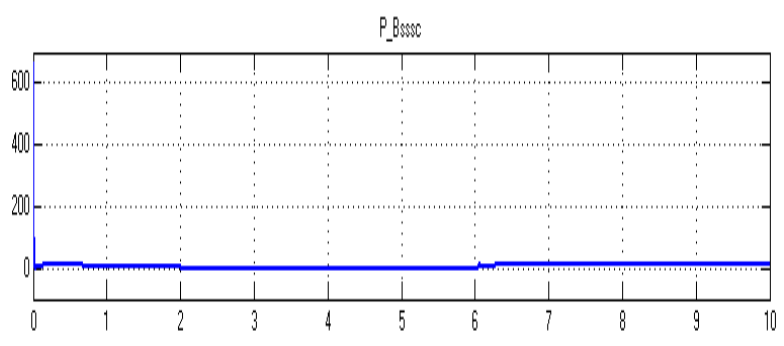

Figure 16: Waveform of active power with POD

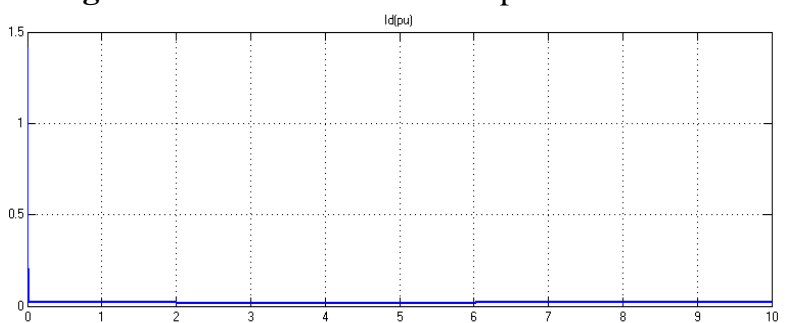

Figure 17: Waveform of Id current with POD

The waveform is having positive value of active power and Id current. It does not have constant positive value, but advantageous is that it is not having negative value of power which was shown in value of power without POD controller.

\section{Conclusion}

It has been found that the SSSC is capable of controlling the flow of power at a desired point on the transmission line. It is also observed that the SSSC injects a fast changing voltage in series with the line irrespective of the magnitude and phase of the line current. Based on obtained simulation results the performance of the SSSC has been examined in a simple two-machine system simply on the selected bus-2, and applications of the SSSC will be extended in future to a complex and multi machine system to investigate the problems related to the various modes of power oscillation in the power systems.

By using 11 bus system with POD controller, it concludes that POD controller is the efficient controller to damp the power oscillation which is shown in the waveform. It gives the benefit not keeping flow of power and line current in negative value and also having good modulating index in regulating modes.

\section{References}

[1] M. Faridi and H. Mae, " Power system stability enhancement using static synchronous series compensator(sssc)", Islamic Azad University-Ahar branch,Ahar,Iran.IEEE,2011.

[2] Kalyan K. Sen “ SSSC-static synchronous series 


\section{International Journal of Science and Research (IJSR) \\ ISSN (Online): 2319-7064}

Index Copernicus Value (2013): 6.14 | Impact Factor (2015): 6.391

compensation: theory, modelling and application" IEEE Transaction on power delivery, Vol.13 , NO.1 , January 1998.

[3] Laszlo gyugi," dynamic compensation of ac transmission line by solid- state synchronous voltage sources" IEEE Transaction on power delivery, Vol. 9, No. 2, April 1994.

[4] Laszlo Gyugyi, fellow IEE Colin. D. Schauder, Member IEEE and Kalyan k. Sen., "static synchronous series compensator: a solid state approach to the series compensator of transmission lines" IEEE transaction on power delivery, vol. 12, No.1, January 1997.

[5] Amir H. Norouzi and A. M. Sharaf, Senior Member, IEEE, "Two control schemes to enhance the dynamic performance of STATCOM and SSSC" IEEE transactions on power delivery, vol. 20, no. 1, january 2005.

[6] Mohan- Mathur , "Thyristor based FACTS controller and electrical transmission system.

[7] K.R.Padiyar, "FACTS controller in power transmission and distribution".

Volume 5 Issue 6, June 2016 www.ijsr.net 